\title{
Identification of Pseudomonas fluorescens using different biochemical tests
}

\author{
Bikram Nepali ${ }^{1}$, Sabin Bhattarai ${ }^{1}$ \& Jiban Shrestha ${ }^{2}$ \\ ${ }^{1}$ Agriculture and Forestry University, Rampur, Chitwan, Nepal. \\ ${ }^{2}$ Nepal Agricultural Research Council, National Commercial Agriculture Research Program, \\ Pakhribas, Dhankuta, Nepal
}

\begin{abstract}
Pseudomonas fluorescens not only enhances the plant growth but also controls the fungal pathogens by production of anti fungal metabolites. The objective of this experiment was to identify $P$. fluorescens using different biochemical tests. This research was carried out in Plant Pathology Laboratory at Agriculture and Forestry University (AFU), Rampur, Chitwan, Nepal. The result of this experiment indicated that $P$. fluorescens gave positive result for Catalase test, Gelatin liquefaction, Fluorescent pigment and Oxidase test but negative result for starch hydrolysis test. The colony of $P$. fluorescens was maximum in maize seed than that of rice seed after two hours of inoculation, whereas higher number of colony was found in rice seed than that of maize seed after twenty four hours of seed inoculation. This findings is useful for identifying colony of $P$. fluorescens per seed which is necessary for better seedling growth and effective biological control of pathogens.
\end{abstract}

\section{Article History}

Received 23 October 2018

Accepted 23 December 2018

Keyword

Inoculation, Rice and

maize seed, Serial

dilution, Pseudomonas

fluorescens

\section{Introduction}

Pseudomonas species encompasses a group of common rod shape, gram negative, one or more polar flagella providing mortality, aerobic in nature, non-spore farming, positive catalase test, positive oxidase test, nonpathogenic saprophytes that colonize soil, water and plant surface environments. It also secretes pyoverdine a fluorescent yellow green siderophore under iron limiting condition. Pseudomonas fluorescent also produces additional type of siderophore such as thioquindobactin (Scales et al., 2014). It is an obligate aerobe, except for some strains that can utilize $\mathrm{NO}_{3}$ as an electron acceptor in place of $\mathrm{O}_{2}$. It is motile by means of multiple polar flagella. Pseudomonas fluorescens has simple nutritional requirements and grows well in mineral salts media supplemented with any of a large number of carbon sources.

$P$. fluorescens is saprophytic fluorescent micro-organism, which are very common in soil around the rhizosphere of various plant species that could improve the plant vigour by incorporating free nutrient and plant growth hormone. In case of cereal crop, it help in 
increasing crop productivity by reducing soil borne disease and stimulating effect on plant growth.

A free living Plant growth promoting rhizobacteria (PGPR) Pseudomonas fluorescens are able to colonize around plant root and incorporate free atmospheric molecule into plant absorbable nutrient form along with improved plant growth and crop yield.

Iron chelation, antibiotic production, enhanced nutrient uptake and seedling emergence promotion and by plant phytohormone production. Siderophore are iron chelating compounds secreted by bacteria on or around the roots that affect the growth of the plants rhizobacteria. The PGPR, being more potent chelators, starve the deleterious rhizobacteria of their iron nutrient, thus protect the plants from the harmful effects of DRB, resulting in better growth and yield (Sakthivel et al., 2009).

Microbial inoculation in seed of crop increases the root biomass production and more colonization of beneficial micro-organism, which are interdependent with these considerations. This micro-organism is natural bio-controllers and improves soil fertility through its own effective Bio fertilizer potential PGPR stains. New research found that P. fluorescens predominant inhabitants of soil and aquatic environments. It plays in the very important role in the purification of pollutants of bioremediation from large chemical industry and secondary metabolites decay material and bio-control some harmful pathogen against crop.

Global food security was threatened by some crop disease and degrading soil fertility. Excess use of chemical fertilizer aiming increase crop yield reporting declining soil fertility lead to desert some place in the world. Root- associated soil bacteria would be the potential solution by improving soil condition and promoting defensive mechanism against various pathogens through improving plant growth mechanism.

The objective of this research was to identify Pseudomonas fluorescens using different biochemical tests and to identify the total number of its colony present in different seed at different time of inoculation.

\section{Materials and Methods}

\section{Experimental Location and Preparation}

This experiment was conducted in Plant Pathology Laboratory at Agriculture and Forestry University (AFU), Rampur, Chitwan, Nepal in October 03, 2018. The liquid composition of Pseudomonas fluorescens were bring form the Agri-care and live-care pvt. Ltd., which was examined through different Bio-chemical test to assure the liquid component consist of bacteria Pseudomonas fluorescens.

\section{Morphological characterization}

Pure cultures of the selected isolates were streaked on King's B agar Petri plates separately for colony development.

\section{Biochemical tests for $\boldsymbol{P}$. fluorescens}

For the identification of $P$. fluorescens, certain biochemical tests were conducted according to Bergey's Manual for Determinative Bacteriology.

\section{Starch hydrolysis}

Filter paper was dipped in a dry old culture suspension and was placed on Petri dishes containing starch agar medium and incubated for two days. The plates were than flooded 
with one per cent iodine solution. A colorless halo around the growth and blue color in the rest of the plates showed utilization of starch by the microorganism.

\section{Gelatin liquefaction}

Filter paper discs were dipped in a day old culture suspension and were placed on Petri dishes containing gelatin nutrient agar medium. The Petri dishes were incubated at $300 \mathrm{C}$ for two days and then flooded with $12.5 \% \mathrm{HgCl}_{2}$ solution. The development of yellow halo around the growth indicates utilization of gelatin.

\section{Fluorescent pigment}

The test tubes containing sterilized Kings B medium were inoculated with the isolate of Pseudomonas sp. incubated for five days and observed. Yellowish green fluorescent pigment observed under UV light ( $365 \mathrm{~nm}$ ) indicated positive results.

\section{Catalase test}

Capillary tubes ( $1 \mathrm{~mm}$ outer isolated by $67 \mathrm{~mm}$ in length were placed in a $50-\mathrm{ml}$ beaker containing about $10 \mathrm{ml}$ of $3 \% \mathrm{H}_{2} \mathrm{O}_{2}$. A positive result is the rapid evolution of oxygen by bubbling. This phenomena is due to the breakdown of hydrogen peroxide $\mathrm{H}_{2} \mathrm{O}_{2}$ in to water and oxygen.

\section{Oxidase test}

Saturate Whatman no.1 filter papers with a $1 \%$ aqueous solution of Diemthyl-pphenlyene- diamine oxalate. Development of red color within a $10 \mathrm{sec}$ indicates a positive reaction.

\section{Inoculation of Pseudomonas into a seed and Serial Dilution}

The seed of Maize (Variety: Rampur Composite) and Rice (Variety: Masuli) were inoculated with Pseudomonas fluorescens at $2.5 \mathrm{ml} \mathrm{kg}^{-1}$ seed in $5 \%$ sugar solution. Let the seed for two hours soaked and secondly twenty four hours. Single seed was dipped into test tube containing a $10 \mathrm{ml}$ of distilled water and shake the tube for one minute. One milliliter of diluted solution from first tube is transfer to second tube containing nine milliliter of distilled water. The process was continue up to six tube and solution made $1 / 1000000$ diluted.

\section{Material for Kings B medium}

Proteose peptone (20g), $\mathrm{K}_{2} \mathrm{HPO}_{4}(1.5 \mathrm{~g}), \mathrm{MgSO}_{4} .7 \mathrm{H}_{2} \mathrm{O}_{4} \quad(1.5 \mathrm{~g})$, Agar $(15 \mathrm{~g})$, Glycerol $(1.5 \mathrm{~mL})$ and water (1 liter) were used in this experiment.

\section{Results and Discussion}

The entire test showed the presence of Pseudomonas fluorescens in the liquid. When the UV is ray was passed into $P$. Fluorescens, a shiny bluish yellow green fluorescent pigment was observed (Figure 1).

Much of the impetus in the study of "unusual" Gram-negative bacilli from clinical sources, was derived from King in Atlanta. The production of a fluorescent pigment on King's medium B was characteristic of most isolates of $P$. putida, $P$. fluorescens and $P$. aeruginosa. $P$. fluorescens perform the best typical gluconate (almost always positive), urea (positive after 
2-3 days), casein (positive), and gelatin (positive) reactions at room temperature (King and Phillips, 1978).

Non-fermenting, catalase-positive Gram-negative bacilli that grow on nutrient agar are often isolated in clinical laboratories. Biochemical techniques appropriate to a typical clinical microbiology laboratory, and for the most part described in Cowan and Steel's Manual for the identification of medical bacteria. On the basis of the oxidation-fermentation test and further tests for oxidase activity and motility, the organisms were allocated to one of several subgroups on the model of Cowan and Steel. However, it was found that the production of alkali in the oxidation-fermentation test was a very useful characteristic and had therefore differentiated it from the "no reaction" group of Cowan and Steel (King and Phillips, 1978).

Solubilization of mineral phosphates and mobilization of other essential nutrients by PGPR also helps in growth improvement of plants. The cell wall of plant cells are mainly composed of cellulose, which was embedded in an amorphous polysaccharide matrix of hemicelluloses, pectin and some glycols and proteins (Meyer and Abdallah, 1978). Also oxidized inositols served as non cellulosic cell wall components.

Table 1. Biochemical characteristics of Pseudomonas fluorescens

\begin{tabular}{lll}
\hline No. & Biochemical tests & Identification of $\boldsymbol{P}$. fluorescens \\
\hline 1 & Starch hydrolysis & Negative \\
2 & Gelatin liquefaction & Positive \\
3 & Fluorescent pigment & Positive \\
4 & Catalase test & Positive \\
5 & Oxidase test & Positive \\
\hline
\end{tabular}

Pseudomonas fluorescens gave positive result for Catalase test, Gelatin liquefaction, Fluorescent pigment and Oxidase test but negative result for starch hydrolysis test.

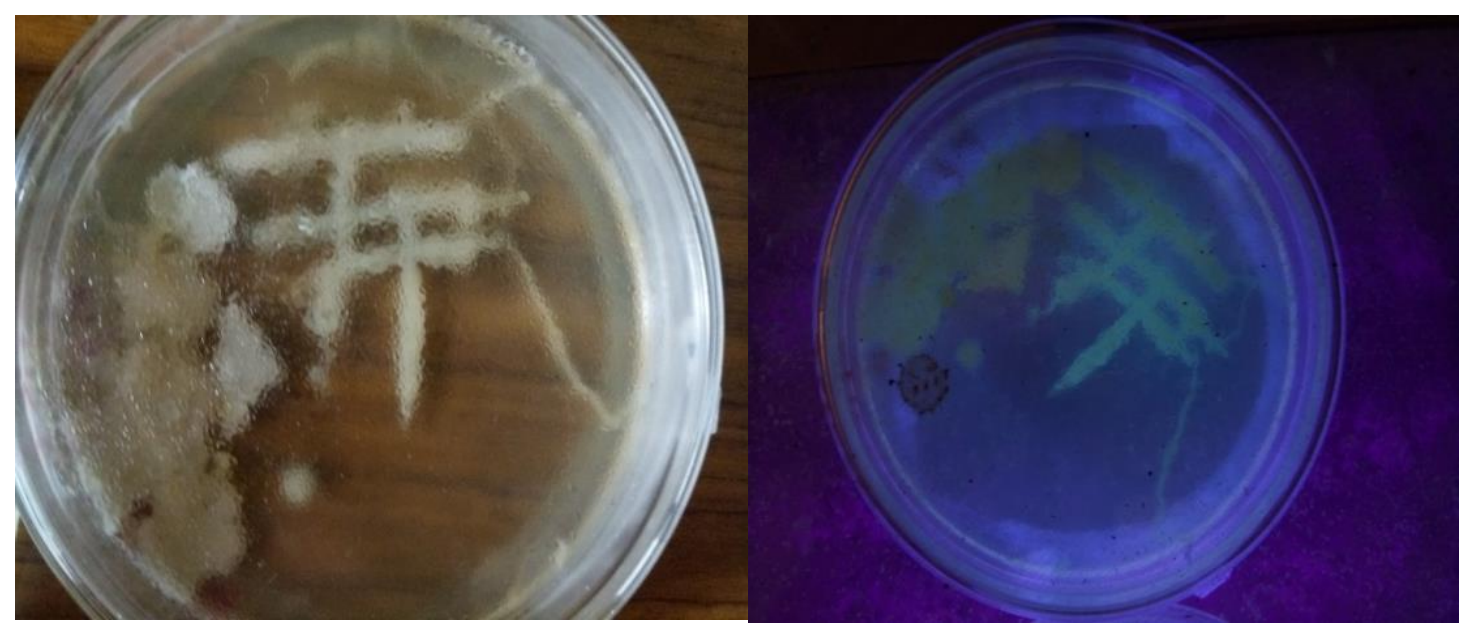

Figure 1. Fluorescent test under UV ray.

\section{Colony of $P$. fluorescens per seed}

After serial dilution to $10^{6}$ of individual seed of Maize and Rice, which was let growth for one day in kings $\mathrm{B}$ medium (six media) at $35^{\circ} \mathrm{C}$. Colony of $P$. Fluorescens was found to be 
higher after two hours of inoculation than that of twenty four hours. Similarly, the higher colony was found in maize seed than rice after two hours and vice-versa after twenty fours respectively. It was count on an average at two hours of inoculation was $2.17^{*} 10^{8}(\mathrm{cfu} / \mathrm{ml} / \mathrm{seed})$ for rice and $1.81^{*} 10^{8}(\mathrm{cfu} / \mathrm{ml} / \mathrm{seed})$ for maize, whereas colony was count as $1.35^{*} 10^{8}(\mathrm{cfu} / \mathrm{ml} / \mathrm{seed})$ and $1.2^{*} 10^{8}(\mathrm{cfu} / \mathrm{ml} / \mathrm{seed})$ for maize and rice respectively.

$*_{\text {i.e. }} \mathrm{cfu}=$ colony forming units

Table 2. Colony of $\boldsymbol{P}$. fluorescens per inoculated seed at different time period

\begin{tabular}{lll}
\hline \multirow{2}{*}{ Particulars } & \multicolumn{2}{c}{ Time } \\
\cline { 2 - 3 } Maize & $2 \mathrm{hrs}$ & $24 \mathrm{hrs}$ \\
\cline { 2 - 3 } & $1.69 * 10^{8} \mathrm{cfu} / \mathrm{ml} / \mathrm{seed}$ & $1.27 * 10^{8} \mathrm{cfu} / \mathrm{ml} / \mathrm{seed}$ \\
& $1.94^{*} 10^{8} \mathrm{cfu} / \mathrm{ml} / \mathrm{seed}$ & $1.53^{*} 10^{8} \mathrm{cfu} / \mathrm{ml} / \mathrm{seed}$ \\
& $1.80^{*} 10^{8} \mathrm{cfu} / \mathrm{ml} / \mathrm{seed}$ & $1.26^{*} 10^{8} \mathrm{cfu} / \mathrm{ml} / \mathrm{seed}$ \\
\hline \multirow{2}{*}{ Rice } & $2.18^{*} 10^{8} \mathrm{cfu} / \mathrm{ml} / \mathrm{seed}$ & $8.9^{*} 10^{7} \mathrm{cfu} / \mathrm{ml} / \mathrm{seed}$ \\
& $2.12^{*} 10^{8} \mathrm{cfu} / \mathrm{ml} / \mathrm{seed}$ & $1.28^{*} 10^{8} \mathrm{cfu} / \mathrm{ml} / \mathrm{seed}$ \\
& $2.21 * 10^{8} \mathrm{cfu} / \mathrm{ml} / \mathrm{seed}$ & $1.43^{*} 10^{8} \mathrm{cfu} / \mathrm{ml} / \mathrm{seed}$ \\
\hline
\end{tabular}

*cfu=colony forming units.

The prevalence of pseudomonas spp. was $68 \%$ and $58 \%$ with mean count $9.02 \times 10^{4} \pm 2.87 \times 10^{4}$ and $2.43 \times 10^{5} \pm 9.32 \times 10^{4}$ for Damietta and kariesh cheese respectively. Pseudomonas spp were not detected in Feta cheese. The most prevalent spp was $p$. fluorescens (35.14\% and 45.5\%)

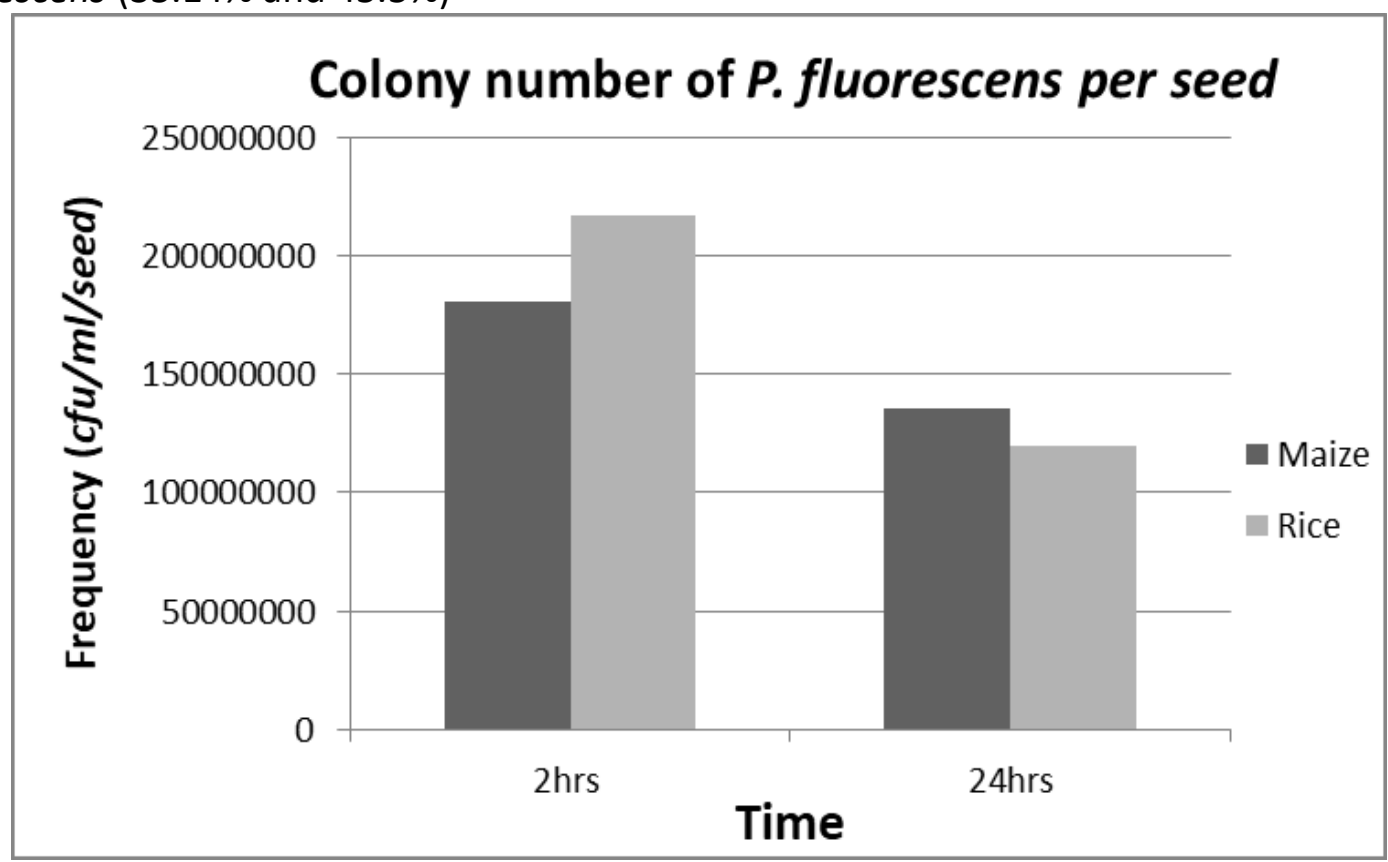

Figure 2. Colony of $P$. fluorescens per seed with respect to time.

while $P$. aeruginosa $(21.26 \%$ and $15.2 \%) ; P$. putida $(27 \%$ and $18.2 \%)$ and $P$. stutzeri (16.21\%and 21.21\%) for Damietta and kariesh cheese respectively (El-Leboudy et al., 2015). Treatments, which were nominal target concentrations of SDP (as active ingredient) of 50, 100,200 , and 300 milligrams per liter (mg/L), were continuously applied for 24 hours (Luoma et al., 2015). Damietta cheesewere positive samples for pseudomonas spp. with mean count $9.02 \times 104 \pm 2.8 \times 104$. 


\section{Conclusions}

Pseudomonas fluorescens a Bio-control agent against various plant diseases was most effective after two hours of inoculation in larger size seed than that of small size seed, whereas soaking of inoculated small size seed for twenty four hours result grater colony per seed.

\section{Aknowledgements}

The authors were grateful to Agriculture and Forestry University, Rampur, Chitwan, Nepal for providing Pathology Lab to conduct this experiment and Agricare Nepal Pvt. Ltd. for providing the strain of Pseudomonas fluorescens

\section{References}

El-Leboudy, A. A., Amer, A. A., Nasief, M. E. \& Eltony, S. M. (2015). Occurrence and Behavior of Pseudomonas Organisms in White Soft Cheese. Alexandria Journal of Veterinary Sciences. 44(1): 74. https://doi.org/10.5455/ajvs.166387

King, A. \& Phillips, I. (1978).The identification of pseudomonads and related bacteria in a clinical laboratory. J Med Microbiol. 11(2): 165-76.

Luoma, J.A., Weber, K.L. \& Mayer, D.A. (2015). Exposure-related effects of Pseudomonas fluorescens, strain CL145A, on coldwater, coolwater, and warmwater fish: U.S. Geological Survey Open-File Report 2015-1104, 1632 p., http://dx.doi.org/10.3133/ofr20151104.

Meyer, J. M., \& Abdallah, M. A. (1978). The Fluorescent Pigment of Pseudomonas fluorescens: Biosynthesis, Purification and Physicochemical Properties. Journal of General Microbiology. 107(2): 319-328. https://doi.org/10.1099/00221287-107-2-319

Sakthivel, U., Mahalakshmi, S. \& Karthikeyan, B. (2009). Studies on isolation and characterization and its (Pseudomonas fluorescens) on yield of tomato. Methods. 1(1): 33-39.

Scales, B. S., Dickson, R. P., Lipuma, J. J. \& Huffnagle, G. B. (2014). Microbiology, genomics, and clinical significance of the Pseudomonas fluorescens species complex, an unappreciated colonizer of humans. Clinical Microbiology Reviews. 27(4): 927-948. https://doi.org/10.1128/CMR.00044-14. 